\title{
Prémio Luso-Espanhol Conferência Lourenço-Madinaveitia
}

A atribuição do Prémio, feita alternadamente pela SPQ e pela RSEQ, coube em 2011 à SPQ. O júri, presidido por Mário Berberan e Santos, Presidente da $S P Q$, e tendo por vogais José Cavaleiro, José Costa Lima, José Moura, Maria José Calhorda e Sebastião Formosinho, decidiu, por unanimidade, atribuir o prémio ao Professor Miguel Angel Yus Astiz, da Universidade de Alicante. O Prof. Miguel Yus proferirá durante o ano de 2012 uma série de conferências em universidades portuguesas sobre matérias da sua especialidade, e cujo calendário será anunciado oportunamente.

\section{Nota Biográfica do Professor Miguel Yus}

Miguel Yus nasceu em Saragoça em 1947, tendo estudado Química (1969) e realizado o seu Doutoramento na universidade desta cidade. Depois de dois anos de pós doutoramento no Max Planck Institut für Kohlenforschung de Mülheim a.d. Ruhr (Alemanha), regressou à universidade de Oviedo, onde foi promovido a Professor Adjunto em 1977 e a Catedrático em 1987. Em 1988 transferiu-se para a Universidade de Alicante como Catedrático de Química Orgânica, sendo atualmente o Diretor do Instituto de Síntese Orgânica (ISO) desde a sua criação. O Dr. Yus foi Professor Visitante em diferentes instituições, como o ETH e as universidades de Oxford, Harvard, Uppsala, Marselha, Tucson, Okayama, Paris, Estrasburgo, Tóquio e Kyoto. É coautor de mais de 500 publicações, principalmente no campo do desenvolvimento de novas metodologias envolvendo compostos organometálicos. Miguel Yus proferiu mais de 150 conferências, a maior parte fora de Espanha. Entre outros, recebeu o Spanish-French Prize (1999), duas vezes o Japan Society for the Promotion of Science Prize (Okayama 2000 e Kyoto 2007), o Stiefvater Memorial Lectureship Award (Lincoln 2001), o Nagase Science and Technology Foundation Fellowship (Kyoto 2003), o Prémio Fundeun-Iberdrola (Alicante 2007) e foi conferencista na Conferência Serratosa 2010. O Dr. Yus fez parte da Comissão Editorial de cerca de 15 revistas internacionais, entre elas Tetrahedron e Tetrahedron Letters (até 2008), European Journal of Organic Chemistry (até 2009), Chemistry Letters, The Chemical Record, Current Organic Chemistry, Current Chemical Biology, Jordan Journal of Chemistry e Trends in Organic Che-

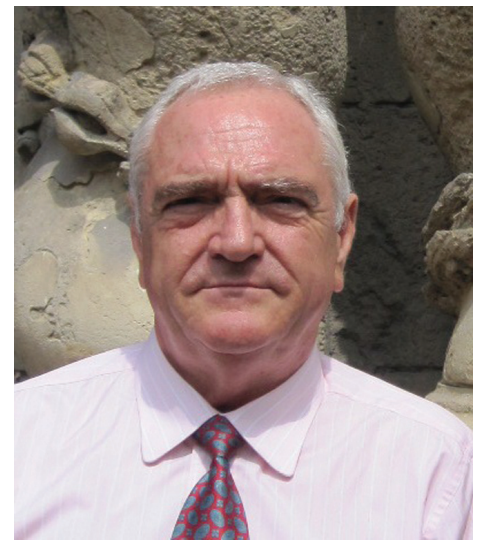

mistry, sendo ainda Editor Regional de Letters in Organic Chemistry e The World Journal of Chemistry. Desde novembro de 2011 é membro da Academia Europeia de Ciências e Artes. Os seus interesses de investigação centram-se em compostos organometálicos funcionalizados de elevada reatividade e sua aplicação em síntese orgânica, ativação de metais, novos catalisadores metálicos incluindo nanopartículas, e síntese assimétrica especialmente na sua componente catalítica. Miguel Yus e outros membros do ISO fundaram recentemente a empresa MEDALCHEMY S. L. para comercializar produtos de química fina.

Helder Gomes (bquimica@ipb.pt) www.spq.pt

\section{$7^{\circ}$ Encontro Nacional de Cromatografia}

O $7^{\circ}$ Encontro Nacional de Cromatografia (7ENC) decorreu na Faculdade de Ciências da Universidade do Porto (FCUP) entre 9 e 11 de janeiro do corrente ano, tendo o evento sido participado por mais de duzentos conferencistas vindos de todo o país, e também de Espanha e do Brasil, e tido a adesão de diversos stands de empresas nacionais e estrangeiras da especialidade. Comece-se por referir a excelente organização levada a cabo pela Comissão Organizadora local, liderada pelo Prof. Aquiles Barros do Departamento de Química e Bioquímica da FCUP, e até atribuir um voto de louvor ao Dr. Luís Gonçalves, pela grande capacidade de trabalho, dedicação e desempenho demonstrados.

Conforme vem sendo habitual, foram convidados dois reputados cientistas estrangeiros, nomeadamente, o Prof. Michal Holčapek da University of Pardubice (República Checa) e a Profa. Maria Eugênia Queiroz do Departamento de Química da Faculdade de Filosofia, Ciências e Letras de Ribeirão Preto, Universidade de São Paulo (Brasil), que proferiram lições plenárias de excelência sobre os desenvolvimentos mais recentes associados às técnicas cromatográficas. $\mathrm{Na}$ totalidade, foram efetuadas mais de cento e cinquenta apresentações científicas, entre lições plenárias, meias-plenárias, comunicações orais e posters, tendo o denominador comum sido uma vez mais a partilha de experiências entre todos os participantes que estudam, desenvolvem e aplicam as técnicas cromatográficas. Durante o evento houve uma clara adesão de jovens conferencistas, tendo as empresas que patrocinaram o evento atribuído prémios às melhores comunicações apresentadas.

Formado há uma dúzia de anos, o grupo de Cromatografia da Sociedade Portuguesa de Química (SPQ) 
parece estar consolidado e continuará seguramente o longo caminho de divulgar as técnicas cromatográficas na academia, indústria e sociedade em geral, tendo como horizonte, a qualidade científica e a manutenção da reputação até aqui reconhecida. Refira-se que, desde 2011, a SPQ é membro da "European Society for

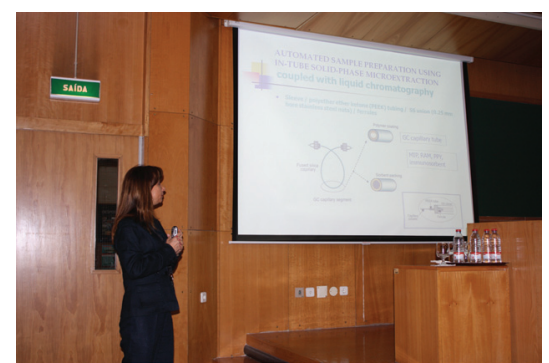

Sessão plenária proferida pela Profa. Maria Eugênia Queiroz (Universidade de São Paulo, Brasil)
Separation Science" (EuSSS), que tem como principal missão a criação de uma plataforma europeia de apoio à ciência de separação.

Para o biénio 2012-13, o grupo de Cromatografia da SPQ será presidido pelo Prof. João Queiroz, estando já agendado o $8^{\circ}$ Encontro Nacional de

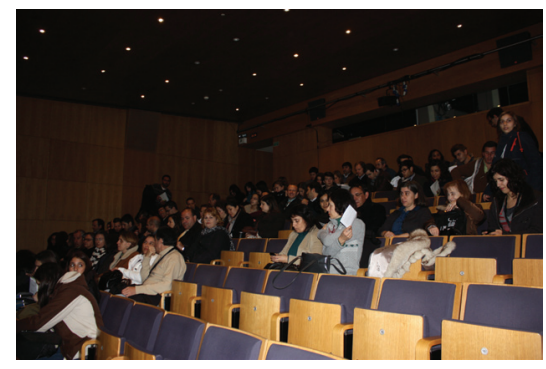

Assistência do 7ENC
Cromatografia, a ter lugar na Universidade da Beira Interior em dezembro de 2013

José Manuel F. Nogueira

(nogueira@fc.ul.pt)

Representante da SPQ na European

Society for Separation Science (EuSSS)

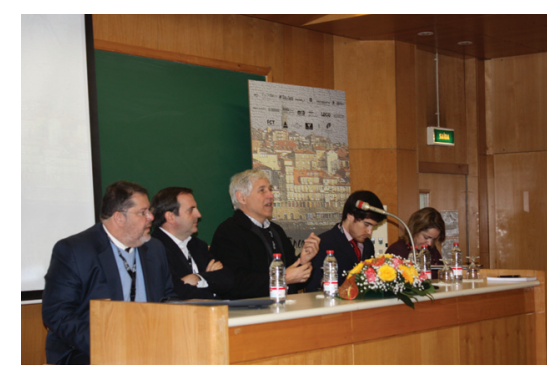

Sessão de encerramento do 7ENC com a entrega dos prémios

\section{6aㅡ Conferênela Europeia de Química Analítica}

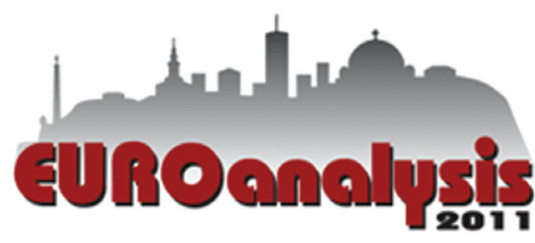

Entre os dias 11 e 15 de setembro de 2011, realizou-se em Belgrado, capital da Sérvia, a $16^{a}$ edição da Conferência Europeia de Química Analítica (EUROANALYSIS 16), da iniciativa da Divisão de Química Analítica da EuCheMS.

Com o tema "Challenges in Modern Analytical Chemistry", contou com largas centenas de participantes de cerca de 60 países, tendo sido apresentadas 10 Lições Plenárias, 21 Lições Convidadas, Comunicações Orais em número superior a 100 e cerca de 500 apresentações em Painel, distribuídas por 3 sessões. Celebrando um dos temas do Ano Internacional da Química, AIQ 2011, houve ainda uma Sessão especial dedicada a Madame Curie. A EUROANALYSIS 16 foi também o palco para a Lição Europeia "The Expanding Scope of Analytical Atomic Spectroscopy: Isotopes, Molecules and Nanoparticles via Mass Spectrometry", proferida pelo Prof. Alfredo Sanz-Medel (Univer- sidade de Oviedo-Espanha) e a Lição Robert Kelnner "Diving Deep Into the Chemistry of Brain" apresentada pelo galardoado Prof. Jonas Berguist (Universidade de Uppsala - Suécia). Um programa bastante preenchido ainda permitiu os Seminários da Hora do Almoço, o que constitui uma nova experiência, em que várias empresas de equipamentos laboratoriais presentes no certame apresentaram os seus desenvolvimento tecnológicos mais recentes. Como já vem sendo habitual, o dia que antecedeu a Conferência foi preenchido com cursos em temas emergentes, "Mass Spectrometry and Applications in the Pharmaceutical Industry", "Chemometrics in ExcelInteractive Educational Programme" e "Quality and Reliability in Analytical Chemistry". Pode ser consultada informação mais detalhada em http:// www.euroanalysis2011.rs/program.

Apraz-me registar o elevado nível científico dos trabalhos, que associado a uma organização impecável, contribui decisivamente para o entusiasmo evidenciado por todos. A expressiva participação de jovens cientistas surge como um indicador da vivacidade desta atividade dos químicos analistas europeus, que atraiu a participação de numeroso grupos de além Europa, designadamente do Brasil. Local de encontro obrigatório das várias gerações, propício à partilha de conhecimento e ao acompanhamento de desenvolvimentos, a EUROANALYSIS 16 contou com significativa participação portuguesa vinda de Aveiro, Funchal, Lisboa e Porto.

O Encerramento foi um novo momento alto, com a passagem do testemunho simbolizado na já famosa "Bandeira da EUROANALYSIS", verde da Irlanda, país que a criou e ofereceu quando, em 1978, organizou, em Dublin, a EUROANALYSIS 3; verde da Química Verde, verde da Esperança e que, entre 1998 e 2000 , orgulhosamente foi residente em Portugal, país organizador da EUROANALYSIS 11. É agora a vez dos colegas da Universidade de Varsóvia-Polónia organizarem a EUROANALYSIS 17, repetindo o feito extraordinário que foi a EUROANALYSIS 5 levada a cabo em 1984 pelo Professor Adam Hullanicki na cidade polaca de Cracóvia.

Maria Filomena Camões (mfcamoes@fc.ul.pt)

Representante da IUPAC

e Membro do Conselho Científico da EUROANALYSIS 16 